\title{
SCIENTIFIC REPORTS

\section{OPEN Role of aldehyde dehydrogenases, alcohol dehydrogenase 1B genotype, alcohol consumption, and their combination in breast cancer in East-Asian women}

\author{
Boyoung Park $\mathbb{B}^{1,2^{*}}$, Ji-Hyun Kim ${ }^{1}$, Eun Sook Lee $\mathbb{B}^{1,3}$, So-Youn Jung ${ }^{1,3}$, See Youn Lee ${ }^{1,3}$, \\ Han-Sung Kang ${ }^{1,3}$, Eun-Gyeong Lee ${ }^{3} \&$ Jai Hong Han $^{3}$
}

The associations between genetic polymorphisms in ADH1B (rs1229984) and ALDH2 (rs671), alcohol consumption, the effect of a combination of the two polymorphisms, and breast cancer risk were studied in a population of East-Asian women. In this study, 623 breast cancer cases and 1845 controls, aged 40 or above, were included. The association between $A L D H 2$ polymorphism and breast cancer risk was validated in 2143 breast cancer cases and 3977 controls. Alcohol consumption increased the risk of breast cancer regardless of $A D H 1 B$ and $A L D H 2$ genotypes. The rs671 polymorphism of $A L D H 2$ was independently associated with increased breast cancer risk $(\mathrm{OR}=1.27,95 \% \mathrm{Cl}=1.02-1.58$ per increment of A). The $A D H 1 B$ rs 1229984 polymorphism, and combined effects of the rs 671 and rs1229984 polymorphisms, did not reveal any significant association with breast cancer. Stratification by menopausal status revealed that $\mathrm{rs} 671$ gene polymorphisms were significantly associated with breast cancer only in postmenopausal women $(O R=1.45,95 \% \mathrm{Cl}=1.03-2.05$ per increment of $A)$. This is the first study to demonstrate an independent association between $A L D H 2$ gene variants and breast cancer in Asian women. Further studies are warranted to further elucidate the etiology of breast cancer as it relates to alcohol consumption in Asian women.

Alcohol consumption is a major risk factor that adversely affects the health of people worldwide ${ }^{1}$. In 2007, the International Agency for Research on Cancer (IARC) classified alcoholic beverages as group 1 carcinogens for the pharynx, larynx, esophagus, liver, colorectum, and female breast based on evidence on the toxicity of ethanol from epidemiological and animal studies ${ }^{2}$. Following alcohol intake, the enzyme alcohol dehydrogenase $(A D H)$ oxidizes alcohol to acetaldehyde, which is highly toxic and carcinogenic to cells and tissues, and is detoxified to acetate by aldehyde dehydrogenases $(A L D H)^{3}$. Thus, gene variants involved in alcohol metabolism and detoxification are also thought to affect the genetic susceptibility to alcohol-associated cancers. Among these, polymorphisms in the $A D H 1 B$ and $A L D H 2$ genes are known to play a pivotal role in cancer development in combination with alcohol consumption ${ }^{4}$. The active $A D H 1 B$ allele results in approximately 40 fold higher metabolism of alcohol to acetaldehyde compared to the inactive allele ${ }^{5}$. In cases with mutant $A L D H 2$ genes, $A L D H 2$ enzyme activity is suppressed and acetaldehyde metabolism in the liver is impaired; subsequent toxic reactions cause symptoms including facial flushing, nausea, headache, or palpitations after alcohol intake; those with deficient variants of $A L D H 2$ genes are likely to either consume less alcohol or be highly addicted ${ }^{2,3,6,7}$.

In general, epidemiological and animal studies have consistently correlated high alcohol intake with increased breast cancer risk in women ${ }^{2}$; however, the gene variants involved in alcohol metabolism or detoxification have only been inconclusively associated with breast cancer risk ${ }^{8,9}$. Considering increases in both alcohol consumption in women ${ }^{10}$ and incidence of breast cancer and related mortality in Asian countries ${ }^{11}$, in combination with the higher distribution of variant genes involved in alcohol metabolism or detoxification in the Asian

${ }^{1}$ Research Institute, National Cancer Center, 323 Ilsan-ro, Ilsandong-gu, Goyang-si, 10408, Korea. ${ }^{2}$ Department of Medicine, Hanyang University College of Medicine, Seoul, Korea. ${ }^{3}$ Hospital, National Cancer Center, 323 Ilsan-ro, Ilsandong-gu, Goyang-si, Gyeonggi-do, 10408, Korea. *email: hayejine@hanmail.net 
population $^{12}$, new studies exploring the associations and interactions among alcohol consumption, related ethanol-metabolizing genes, and breast cancer are warranted.

Thus, in the present study, we investigated the association among genetic, functionally established single nucleotide polymorphisms (SNPs) in $A D H 1 B$ (rs1229984) and ALDH2 (rs671), alcohol consumption, and their combined effects and breast cancer risk in an East-Asian population.

\section{Results}

The general characteristics of the patients with breast cancer from the National Cancer Center (NCC) and age-matched controls from the Korean Genome Epidemiology Study (KoGES) are described in Table 1. Except age distribution and mean age, which were matched between cases and controls, the distribution of the other variables differed significantly between the cases and controls. In particular, the proportion of ever drinkers and those who drink $>12 \mathrm{~g}$ ethanol/day was higher in the breast cancer group.

Table 2 presents the association between alcohol consumption, $A L D H 2$ rs671 polymorphism, $A D H 1 B$ rs1229984 polymorphism, and breast cancer risk. Compared to the non-drinkers, the ever drinkers and those who consumed $12 \mathrm{~g}$ alcohol or more per day exhibited increased association with breast cancer $(\mathrm{OR}=1.27,95 \%$ $\mathrm{CI}=1.01-1.61, P$-value $=0.042 ; \mathrm{OR}=2.15,95 \% \mathrm{CI}=1.28-3.59, P$-value $=0.004)$. The rs671 genotype, although unassociated with breast cancer in an adjusted model, was significantly associated with breast cancer risk after the model was additionally adjusted for daily alcohol intake in patients with a GA or AA genotype compared with those presenting a GG homozygote $(\mathrm{OR}=1.29,95 \% \mathrm{CI}=1.00-1.65, P$-value $=0.045)$ and per increment of $\mathrm{A}(\mathrm{OR}=1.27,95 \% \mathrm{CI}=1.02-1.58, P$-value $=0.032)$. The $A D H 1 B$ rs 1229984 polymorphism did not exhibit any significant association. The combined effects of the $A L D H 2$ rs671 and $A D H 1 B$ rs 1229984 polymorphisms are presented in Appendix Table 2. No significant association was observed between the combination of the two polymorphisms and breast cancer risk.

Table 3 lists the effect of alcohol consumption according to $A L D H 2 / A D H 1 B$ polymorphism. In those homozygous for the GG allele of rs671, the effects of ever consuming alcohol or daily alcohol intake were associated with increased risk of breast cancer $(\mathrm{OR}=1.54,95 \% \mathrm{CI}=1.17-2.04, P$-value $=0.002$; $\mathrm{OR}=2.57,95 \% \mathrm{CI}=1.45-4.53$, $P$-value $=0.001)$. In terms of the rs 1229984 variant of the $A D H 1 B$ gene, those homozygous for TT exhibited a significantly increased risk of breast cancer in both ever drinkers and those who daily consumed $>12 \mathrm{~g}$ day alcohol $(\mathrm{OR}=1.58,95 \% \mathrm{CI}=1.15-2.17, P$-value $=0.005 ; \mathrm{OR}=2.97,95 \% \mathrm{CI}=1.49-5.94, P$-value $=0.002)$; however, in women with a TC or CC genotype, no association was observed between alcohol consumption and breast cancer. When we combined the $A L D H 2 / A D H 1 B$ polymorphisms, those homozygous for the major allele for both rs671 and rs1229984 (GG and TT) presented increased risk of breast cancer in ever drinkers (OR $=1.76$, $95 \% \mathrm{CI}=1.22-2.57, P$-value 0.003$)$ and those who consumed $12 \mathrm{~g}$ alcohol or more per day $(\mathrm{OR}=3.37,95 \%$ $\mathrm{CI}=1.59-7.22, P$-value $=0.002$ ).

Stratification by menopausal status revealed that alcohol consumption was significantly associated with breast cancer in premenopausal women (Table $4 ; \mathrm{OR}=1.75,95 \% \mathrm{CI}=1.27-2.43, P$-value $=0.001$ for ever alcohol drinkers; $\mathrm{OR}=1.53,95 \% \mathrm{CI}=1.08-2.18, P$-value $=0.018$ for those consuming $\leq 12 \mathrm{~g}$ ethanol $/$ day; $\mathrm{OR}=2.87$, $95 \% \mathrm{CI}=1.52-5.40, P$-value $=0.001$ for those consuming $>12 \mathrm{~g}$ ethanol/day, compared with non-drinkers). Nevertheless, polymorphisms in the rs671 gene were significantly associated with breast cancer only in postmenopausal women with dominant alleles $(\mathrm{OR}=1.63,95 \% \mathrm{CI}=1.10-2.40, P$-value $=0.014$ for GA/AA genotype) and in the additive model $(\mathrm{OR}=1.45,95 \% \mathrm{CI}=1.03-2.05, P$-value $=0.032$ for one increment of $\mathrm{A})$, but not for premenopausal women.

After investigating 2143 breast cancer cases and 3977 controls, the polymorphism in the ALDH2 gene showed increased breast cancer risk in all genetic models (Appendix Table 3). The OR of GA/AA compared with that of GG was $1.13(95 \% \mathrm{CI}=1.01-1.27, P$-value $=0.034)$ and an increment in the A allele increased breast cancer risk by 1.14 -fold $(95 \% \mathrm{CI}=1.03-1.26, P$-value $=0.013)$.

\section{Discussion}

This is the first study suggesting that variants of the $A L D H 2$ gene (rs671) increase the risk of breast cancer independently, after adjusting for other covariates such as alcohol consumption, in Asian women, and in particular in postmenopausal women. In this study, both ever consuming alcohol and high dose alcohol consumption $(>12 \mathrm{~g} /$ day) increased the risk of developing breast cancer. However, the association between alcohol consumption and breast cancer was more prominent in those with $A D H 1 B$ His/His or those that were homozygous for the major allele in both $A D H 1 B$ and $A L D H 2$.

The association among ever consuming alcohol, high alcohol consumption $(>12 \mathrm{~g} /$ day), and breast cancer in all women observed in the present study was in accordance with that in previous studies and reviews ${ }^{8,13}$. Previous studies have reported inconsistent results, wherein they evaluated whether menopausal status modifies the effect of the association between alcohol consumption and breast cancer risk ${ }^{8,14}$. In the present study, this association was observed only in premenopausal women. A possible explanation for the nonsignificant result in postmenopausal women could be that fewer women ever consumed alcohol or high alcohol content drinks; thus, the number was insufficient to statistically power our results. Considering that several studies suggest a modified effect of known genetic and environmental factors such as MPO gene polymorphism, family history, obesity, or alcohol use by menopausal status ${ }^{14,15}$, a detailed approach stratified by menopausal status with larger sample size is warranted.

$A D H 1 B$ and $A L D H 2$ are the major enzymes involved in alcohol metabolism in humans. The role of the $A L D H 2$ gene has been widely studied in East-Asian countries because of the low prevalence of its variants in European populations. It has been reported that variants of the $A L D H 2$ gene are correlated with an increased susceptibility to numerous cancers, particularly of the upper digestive organs, such as esophageal or gastric can$\operatorname{cer}^{16,17}$; however, for other cancer types, the results were generally nonsignificant or inconsistent ${ }^{16,18}$. For breast 


\begin{tabular}{|c|c|c|c|c|c|}
\hline & \multicolumn{2}{|c|}{ Cases $(N=623)$} & \multicolumn{2}{|c|}{ Controls $(N=1845)$} & \multirow[b]{2}{*}{$P$-value } \\
\hline & $N$ & $\%$ & $N$ & $\%$ & \\
\hline Age & & & & & 0.995 \\
\hline $40-49$ & 373 & 59.9 & 1105 & 59.9 & \\
\hline $50-59$ & 195 & 31.3 & 575 & 31.2 & \\
\hline $60-$ & 55 & 8.8 & 165 & 8.9 & \\
\hline Mean age (SD) & 49.14 & $(6.68)$ & 49.12 & $(6.70)$ & 0.959 \\
\hline Age at menarche & & & & & $<0.001$ \\
\hline$\leq 15$ & 523 & 83.9 & 896 & 48.6 & \\
\hline$\geq 16$ & 98 & 15.7 & 932 & 50.5 & \\
\hline Unknown & 2 & 0.3 & 17 & 0.9 & \\
\hline Age at first full term pregnancy & & & & & $<0.001$ \\
\hline Nullipara & 55 & 8.8 & 17 & 0.9 & \\
\hline$\leq 23$ & 62 & 10.0 & 575 & 31.2 & \\
\hline $24-26$ & 134 & 21.5 & 702 & 38.0 & \\
\hline$\geq 27$ & 367 & 58.9 & 528 & 28.6 & \\
\hline Unknown & 5 & 0.8 & 23 & 1.2 & \\
\hline Age at menopause & & & & & $<0.001$ \\
\hline Premenopause & 348 & 55.9 & 1085 & 58.8 & \\
\hline$\leq 47$ & 93 & 14.9 & 314 & 17.0 & \\
\hline $48-50$ & 55 & 8.8 & 253 & 13.7 & \\
\hline$\geq 51$ & 100 & 16.1 & 193 & 10.5 & \\
\hline Unknown & 27 & 4.3 & 0 & 0.0 & \\
\hline Body mass index $\left(\mathrm{kg} / \mathrm{m}^{2}\right)$ & & & & & $<0.001$ \\
\hline$\leq 23$ & 306 & 49.1 & 520 & 28.2 & \\
\hline $24-26.99$ & 217 & 34.8 & 717 & 38.9 & \\
\hline$\geq 27$ & 88 & 14.1 & 608 & 33.0 & \\
\hline Unknown & 12 & 1.9 & 0 & 0.0 & \\
\hline Smoking status & & & & & $<0.001$ \\
\hline Never & 570 & 91.5 & 1756 & 95.2 & \\
\hline Ever & 53 & 8.5 & 61 & 3.3 & \\
\hline Unknown & 0 & 0.0 & 28 & 1.5 & \\
\hline Alcohol consumption & & & & & $<0.001$ \\
\hline Never & 391 & 62.8 & 1252 & 67.9 & \\
\hline Ever & 232 & 37.2 & 593 & 32.1 & \\
\hline$\leq 12 \mathrm{~g}$ ethanol/day & 150 & 24.1 & 467 & 25.3 & \\
\hline$>12$ g ethanol/day & 43 & 6.9 & 56 & 3.0 & \\
\hline Unknown & 39 & 6.3 & 70 & 3.8 & \\
\hline \multicolumn{6}{|l|}{ Pathology stage of breast cancer } \\
\hline Stage 0 & 273 & 43.9 & & & \\
\hline Stage 1 & 201 & 32.2 & & & \\
\hline Stage 2 & 118 & 18.9 & & & \\
\hline Stage 3 & 22 & 3.5 & & & \\
\hline Unknown & 9 & 1.5 & & & \\
\hline \multicolumn{6}{|c|}{ Histology grade of breast cancer } \\
\hline Grade 1 & 67 & 10.7 & & & \\
\hline Grade 2 & 272 & 43.6 & & & \\
\hline Grade 3 & 161 & 25.9 & & & \\
\hline Unknown & 123 & 19.7 & & & \\
\hline \multicolumn{6}{|l|}{ Estrogen receptor status } \\
\hline Negative & 269 & 43.1 & & & \\
\hline Positive & 351 & 56.4 & & & \\
\hline Unknown & 3 & 0.5 & & & \\
\hline \multicolumn{6}{|l|}{ Progesterone receptor status } \\
\hline Negative & 310 & 49.8 & & & \\
\hline Positive & 310 & 49.7 & & & \\
\hline Unknown & 3 & 0.5 & & & \\
\hline
\end{tabular}

Table 1. Characteristics of the study population. 


\begin{tabular}{|c|c|c|c|c|c|c|c|c|c|c|}
\hline & \multicolumn{2}{|c|}{ Cases } & \multicolumn{2}{|c|}{ Controls } & \multirow[b]{2}{*}{ Odds ratio $^{a}$} & \multirow[b]{2}{*}{$P$} & \multirow[b]{2}{*}{ Odds ratio $^{b}$} & \multirow[b]{2}{*}{$P$} & \multirow[b]{2}{*}{ Odds ratio ${ }^{c}$} & \multirow[b]{2}{*}{$P$} \\
\hline & $N$ & $\%$ & $N$ & $\%$ & & & & & & \\
\hline \multicolumn{11}{|c|}{ Alcohol consumption } \\
\hline Never & 391 & 62.8 & 1252 & 67.9 & 1 (ref) & & 1 (ref) & & 1 (ref) & \\
\hline Ever & 232 & 37.2 & 593 & 32.1 & $1.25(1.03-1.51)$ & 0.020 & $1.27(1.01-1.61)$ & 0.042 & $1.38(1.08-1.76)$ & 0.010 \\
\hline$\leq 12$ g ethanol/day & 150 & 24.1 & 467 & 25.3 & $1.03(0.83-1.27)$ & 0.799 & $1.11(0.85-1.44)$ & 0.441 & $1.20(0.91-1.57)$ & 0.189 \\
\hline$>12 \mathrm{~g}$ ethanol/day & 43 & 6.9 & 56 & 3.0 & $2.46(1.62-3.71)$ & $<0.001$ & $2.15(1.28-3.59)$ & 0.004 & $2.38(1.41-4.01)$ & 0.001 \\
\hline \multicolumn{11}{|c|}{ ALDH2 rs671 genotype } \\
\hline \multicolumn{11}{|c|}{ Codominant model } \\
\hline GG & 1318 & 71.4 & 428 & 68.7 & 1 (ref) & & 1 (ref) & & 1 (ref) & \\
\hline GA & 483 & 26.2 & 175 & 28.1 & $1.12(0.91-1.37)$ & 0.294 & $1.14(0.89-1.45)$ & 0.306 & $1.26(0.98-1.63)$ & 0.074 \\
\hline AA & 44 & 2.4 & 20 & 3.2 & $1.40(0.80-2.37)$ & 0.222 & $1.44(0.71-2.84)$ & 0.297 & $1.67(0.82-3.31)$ & 0.151 \\
\hline \multicolumn{11}{|l|}{ Dominant model } \\
\hline GG & 1318 & 71.4 & 428 & 68.7 & 1 (ref) & & 1 (ref) & & 1 (ref) & \\
\hline GA/AA & 527 & 28.6 & 195 & 31.3 & $1.14(0.96-1.35)$ & 0.194 & $1.16(0.91-1.47)$ & 0.222 & $1.29(1.00-1.65)$ & 0.045 \\
\hline \multicolumn{11}{|l|}{ Additive model } \\
\hline Increment of A & - & - & - & - & $1.14(0.93-1.39)$ & 0.139 & $1.16(0.94-1.42)$ & 0.173 & $1.27(1.02-1.58)$ & 0.032 \\
\hline \multicolumn{11}{|c|}{ ADH1B rs1229984 genotype } \\
\hline \multicolumn{11}{|c|}{ Co-dominant model } \\
\hline TT & 1036 & 56.2 & 358 & 57.8 & 1 (ref) & & 1 (ref) & & 1 (ref) & \\
\hline TC & 687 & 37.2 & 231 & 37.3 & $0.74(0.80 \mathrm{z}-1.18)$ & 0.780 & $0.91(0.72-1.15)$ & 0.446 & $0.91(0.72-1.15)$ & 0.435 \\
\hline $\mathrm{CC}$ & 122 & 6.6 & 30 & 4.8 & $0.71(0.46-1.07)$ & 0.110 & $0.70(0.42-1.14)$ & 0.164 & $0.71(0.42-1.16)$ & 0.178 \\
\hline \multicolumn{11}{|l|}{ Dominant model } \\
\hline TT & 1036 & 56.2 & 358 & 57.8 & 1 (ref) & & 1 (ref) & & 1 (ref) & \\
\hline $\mathrm{TC} / \mathrm{CC}$ & 809 & 43.8 & 261 & 47.2 & $0.93(0.78-1.12)$ & 0.495 & $0.88(0.71-1.10)$ & 0.275 & $0.88(0.71-1.10)$ & 0.274 \\
\hline \multicolumn{11}{|l|}{ Additive model } \\
\hline Increment of C & - & - & - & - & $0.91(0.78-1.06)$ & 0.224 & $0.88(0.73-1.05)$ & 0.165 & $0.88(0.73-1.06)$ & 0.171 \\
\hline
\end{tabular}

Table 2. Association among alcohol consumption, ALDH2 rs671 polymorphism, ADH1B rs1229984 polymorphism, and breast cancer risk. ${ }^{a}$ Unadjusted odds ratio; ${ }^{b}$ Adjusted for age at menarche, age at first full term pregnancy, age at menopause, body mass index, and smoking status; ${ }^{\mathrm{c}}$ Additionally adjusted for alcohol consumption (for the association with ALDH2 or ADH1B) or ALDH2/ADH1B (for the association with alcohol consumption).

cancer, only three studies have investigated the role of the $A L D H 2$ gene (rs671); however, none of them reported a significant association. In all three studies, the controls were recruited from women who visited the same hospital as the patients ${ }^{19-21}$. Although controls did not have cancer or other systemic diseases, and the proportion of alcohol consumption was in accordance with that in our study population, their inclusion may not substitute for the general population due to Berkson's bias, a type of selection bias ${ }^{22}$. In our study population, the controls belonged to a population-based cohort, presumably free of Berkson's bias, thus indicating a better reflection of females in general, and even after adjusting for alcohol consumption, polymorphisms in the ALDH2 gene independently increased breast cancer risk. The association between $A L D H 2$ gene variants and breast cancer was validated in independent cases and all sampled control populations. In addition, compared with the previous studies in which the number of breast cancer patients and controls was less than $500^{19-21}$, the present study has a higher number of patients and 1:3 matching was used to increase the statistical power. In combination with the possible side effects of paclitaxel, a chemotherapeutic agent, due to alcohol's role as a solvent ${ }^{23}$ women with the GA/AA genotype of $A L D H 2$ would be highly susceptible to not only breast cancer but also side effects of breast cancer treatment, and are therefore a population with a potentially high risk for delterious health effects.

$A D H 1 B$ action results in higher blood acetaldehyde levels, which can increase DNA damage and lead to can$\operatorname{cer}^{24}$. In people with $A D H 1 B$ His/His, the activity of $A D H 1 B$ is enhanced, followed by rapid accumulation of acetaldehyde $^{25}$. In epidemiological studies, $A D H 1 B$ polymorphism has been associated with tumors of the upper digestive organs ${ }^{4}$ including esophageal cancer ${ }^{26}$. In terms of breast cancer, $A D H 1 B$ itself did not present any association in most previous studies ${ }^{19,27,28}$. One study reported a marginally protective association for $A D H 1 B$ IVS1 + 896 A > G with breast cancer risk; however, the same SNP considered in this study did not exhibit any association $^{29}$. Another study reported an interactive effect of $A D H 1 B$ and alcohol consumption on breast cancer risk $^{27}$. In the present study, although we did not identify a significant association between $A D H 1 B$ polymorphism and breast cancer risk, a decreasing trend was observed in those with the $\mathrm{C}$ allele, in particular the homozygotes of the $\mathrm{C}$ allele, which was consistent with previous studies ${ }^{29}$. Another study reported that the effects of the $A D H 1 B$ and $A L D H 2$ genes were mediated via alcohol consumption and decreased hepatocellular carcinoma risk ${ }^{30}$, which was not consistent with a previous meta-analysis ${ }^{16}$. In a study by Lie et al., the population included chronic hepatitis $B$ carriers and the effect of alcohol was higher ${ }^{30}$ than seen in the present study or other studies conducted in the Korean population ${ }^{31}$. Considering the subgroup of women with possibly higher alcohol susceptibility, the 


\begin{tabular}{|c|c|c|c|c|c|c|c|c|}
\hline & \multicolumn{2}{|c|}{ Cases } & \multicolumn{2}{|c|}{ Controls } & \multirow[b]{2}{*}{ Odds ratio ${ }^{a}$} & \multirow[b]{2}{*}{$P$-value } & \multirow[b]{2}{*}{ Odds ratio ${ }^{b}$} & \multirow[b]{2}{*}{$P$-value } \\
\hline & $N$ & $\%$ & $N$ & $\%$ & & & & \\
\hline \multicolumn{9}{|c|}{ ALDH2 rs671 genotype; GG } \\
\hline \multicolumn{9}{|c|}{ Alcohol consumption } \\
\hline Never & 225 & 52.6 & 801 & 60.8 & 1 (ref) & & 1 (ref) & \\
\hline Ever & 203 & 47.4 & 517 & 39.2 & $1.40(1.12-1.74)$ & 0.003 & $1.54(1.17-2.04)$ & 0.002 \\
\hline$\leq 12$ g ethanol/day & 129 & 30.1 & 404 & 30.7 & $1.14(0.89-1.45)$ & 0.301 & $1.33(0.98-1.81)$ & 0.064 \\
\hline$>12 \mathrm{~g}$ ethanol/day & 41 & 9.6 & 52 & 3.9 & $2.81(1.81-4.33)$ & $<0.001$ & $2.57(1.45-4.53)$ & 0.001 \\
\hline \multicolumn{9}{|c|}{ ALDH2 rs671 genotype; GA/AA } \\
\hline \multicolumn{9}{|c|}{ Alcohol consumption } \\
\hline Never & 166 & 85.1 & 451 & 85.6 & 1 (ref) & & 1 (ref) & \\
\hline Ever & 29 & 14.9 & 76 & 14.4 & $1.04(0.64-1.63)$ & 0.879 & $1.34(0.73-2.41)$ & 0.336 \\
\hline$\leq 12 \mathrm{~g}$ ethanol/day & 21 & 10.8 & 63 & 12.0 & $0.91(0.52-1.51)$ & 0.711 & $1.15(0.58-2.20)$ & 0.685 \\
\hline$>12 \mathrm{~g}$ ethanol/day & 2 & 1.0 & 4 & 0.8 & $1.36(0.19-7.03)$ & 0.725 & $3.73(0.45-24.11)$ & 0.171 \\
\hline \multicolumn{9}{|c|}{ ADH1B rs1229984 genotype; TT } \\
\hline \multicolumn{9}{|c|}{ Alcohol consumption } \\
\hline Never & 224 & 62.6 & 704 & 68.0 & 1 (ref) & & 1 (ref) & \\
\hline Ever & 134 & 37.4 & 332 & 32.0 & $1.27(0.99-1.63)$ & 0.063 & $1.58(1.15-2.17)$ & 0.005 \\
\hline$\leq 12$ g ethanol/day & 85 & 23.7 & 264 & 25.5 & $1.01(0.76-1.34)$ & 0.936 & $1.32(0.93-1.88)$ & 0.121 \\
\hline$>12$ g ethanol/day & 28 & 7.8 & 32 & 3.1 & $2.75(1.61-4.67)$ & $<0.001$ & $2.97(1.49-5.94)$ & 0.002 \\
\hline \multicolumn{9}{|c|}{ ADH1B rs1229984 genotype; TC/CC } \\
\hline \multicolumn{9}{|c|}{ Alcohol consumption } \\
\hline Never & 163 & 62.5 & 548 & 67.7 & 1 (ref) & & 1 (ref) & \\
\hline Ever & 98 & 37.5 & 261 & 32.3 & $0.26(0.94-1.69)$ & 0.116 & $1.24(0.86-1.79)$ & 0.250 \\
\hline$\leq 12$ g ethanol/day & 65 & 24.9 & 203 & 25.1 & $1.08(0.77-1.49)$ & 0.661 & $1.10(0.73-1.66)$ & 0.634 \\
\hline$>12 \mathrm{~g}$ ethanol/day & 15 & 5.7 & 24 & 3.0 & $2.10(1.06-4.06)$ & 0.030 & $1.93(0.81-4.48)$ & 0.128 \\
\hline \multicolumn{9}{|c|}{ ALDH2 rs671 \& ADH1B rs1229984 genotype; GG and TT } \\
\hline \multicolumn{9}{|c|}{ Alcohol consumption } \\
\hline Never & 133 & 52.6 & 449 & 60.8 & 1 (ref) & & 1 (ref) & \\
\hline Ever & 120 & 47.4 & 289 & 39.2 & $1.40(1.05-1.87)$ & 0.021 & $1.76(1.22-2.57)$ & 0.003 \\
\hline$\leq 12 \mathrm{~g}$ ethanol/day & 75 & 29.6 & 226 & 30.6 & $1.12(0.81-1.55)$ & 0.493 & $1.46(0.97-2.21)$ & 0.068 \\
\hline$>12 \mathrm{~g}$ ethanol/day & 27 & 10.7 & 30 & 4.1 & $3.04(1.74-5.30)$ & $<0.001$ & $3.37(1.59-7.22)$ & 0.002 \\
\hline \multicolumn{9}{|c|}{ ALDH2 rs671 and ADH1B rs1229984 genotype; GA or TC } \\
\hline \multicolumn{9}{|c|}{ Alcohol consumption } \\
\hline Never & 216 & 67.9 & 682 & 72.3 & 1 (ref) & & 1 (ref) & \\
\hline Ever & 102 & 32.1 & 261 & 27.7 & $1.23(0.93-1.62)$ & 0.135 & $1.21(0.85-1.70)$ & 0.291 \\
\hline$\leq 12 \mathrm{~g}$ ethanol/day & 70 & 22 & 205 & 21.7 & $1.08(0.79-1.47)$ & 0.636 & $1.09(0.74-1.60)$ & 0.660 \\
\hline$>12$ g ethanol/day & 14 & 4.4 & 23 & 2.4 & $1.92(0.95-3.76)$ & 0.060 & $1.76(0.73-4.08)$ & 0.197 \\
\hline \multicolumn{9}{|c|}{ ALDH2 rs671 and ADH1B rs1229984 genotype; AA or CC } \\
\hline \multicolumn{9}{|c|}{ Alcohol consumption } \\
\hline Never & 39 & 79.6 & 121 & 73.8 & 1 (ref) & & 1 (ref) & \\
\hline Ever & 10 & 20.4 & 43 & 26.2 & $0.72(0.32-1.52)$ & 0.410 & $0.95(0.32-2.68)$ & 0.928 \\
\hline$\leq 12$ g ethanol/day & 5 & 10.2 & 36 & 22 & $0.43(0.14-1.09)$ & 0.100 & $0.63(0.14-2.25)$ & 0.506 \\
\hline$>12$ g ethanol/day & 2 & 4.1 & 3 & 1.8 & $2.07(0.27-12.92)$ & 0.435 & $1.70(0.12-25.00)$ & 0.681 \\
\hline
\end{tabular}

Table 3. Association between alcohol consumption and breast cancer risk according to ALDH 2 rs671 or ADH1B rs1229984 polymorphism. a Unadjusted odds ratio; ${ }^{b}$ Adjusted for age, age at menarche, age at first full term pregnancy, age at menopause, body mass index, and smoking status.

effects of the $A D H 1 B$ and $A L D H 2$ genes on alcohol drinking behavior and breast cancer risk might require further investigation.

In the present study, the association between alcohol consumption and breast cancer risk stratified by ALDH2 and $A D H 1 B$ polymorphism status, despite the presence of variants and alcohol intake, specifically a high dose of alcohol intake, increased the risk of breast cancer. Among the variants studied, those with a TT genotype for rs1229984 exhibited higher risk of breast cancer in ever drinkers or in those who consume more than $12 \mathrm{~g}$ of ethanol per day. These results are contradictory to those from a study in German women, wherein a reduction in breast cancer risk associated with $12 \mathrm{~g}$ or more alcohol consumption per day was observed ${ }^{27}$. The frequency of the His/Arg allele of $A D H 1 B$ gene varies among populations, specifically the Asian and European populations ${ }^{32}$, and is based on diet or other lifestyle factors; moreover, other interacting genes may presumably lead to different results between studies. 


\begin{tabular}{|c|c|c|c|c|c|c|c|c|c|c|c|c|}
\hline & \multicolumn{6}{|c|}{ Premenopausal } & \multicolumn{6}{|c|}{ Postmenopausal } \\
\hline & $N$ & $\%$ & $N$ & $\%$ & Odds ratio $^{\mathrm{a}}$ & $\mathbf{P}$ & $N$ & $\%$ & $N$ & $\%$ & Odds ratio $^{a}$ & $P$ \\
\hline \multicolumn{13}{|c|}{ Alcohol consumption } \\
\hline Never & 197 & 56.6 & 695 & 64.1 & 1 (ref) & & 187 & 73.3 & 557 & 73.3 & 1 (ref) & \\
\hline Ever & 151 & 43.4 & 390 & 35.9 & $1.75(1.27-2.43)$ & 0.001 & 68 & 26.7 & 203 & 26.7 & $1.30(0.85-1.96)$ & 0.222 \\
\hline$\leq 12 \mathrm{~g}$ ethanol/day & 99 & 28.4 & 309 & 28.5 & $1.53(1.08-2.18)$ & 0.018 & 43 & 16.9 & 158 & 20.8 & $1.09(0.69-1.73)$ & 0.717 \\
\hline$>12 \mathrm{~g}$ ethanol/day & 33 & 9.5 & 41 & 3.8 & $2.87(1.52-5.40)$ & 0.001 & 9 & 3.5 & 15 & 2.0 & $2.40(0.72-7.63)$ & 0.144 \\
\hline \multicolumn{13}{|c|}{ ALDH2 rs671 genotype } \\
\hline \multicolumn{13}{|c|}{ Co-dominant model } \\
\hline GG & 246 & 70.7 & 759 & \begin{tabular}{|l|l|}
70 \\
\end{tabular} & 1 (ref) & & 168 & \begin{tabular}{|l|}
65.9 \\
\end{tabular} & 559 & 73.6 & 1 (ref) & \\
\hline GA & 90 & 25.9 & 301 & 27.7 & $1.03(0.73-1.46)$ & 0.860 & 80 & 31.4 & 182 & 23.9 & $1.67(1.12-2.49)$ & 0.011 \\
\hline AA & 12 & 3.4 & 25 & 2.3 & $2.12(0.84-5.15)$ & 0.102 & 7 & 2.7 & 19 & 2.5 & $1.12(0.32-3.49)$ & 0.846 \\
\hline \multicolumn{13}{|l|}{ Dominant model } \\
\hline GG & 246 & 70.7 & 759 & 70 & 1 (ref) & & 168 & 65.9 & 559 & 73.6 & 1 (ref) & \\
\hline GA/AA & 102 & 29.3 & 326 & 30 & $1.10(0.78-1.54)$ & 0.594 & 87 & 34.1 & 201 & 26.4 & $1.63(1.10-2.40)$ & 0.014 \\
\hline \multicolumn{13}{|l|}{ Additive model } \\
\hline Increment of A & - & - & - & - & $1.16(0.86-1.56)$ & 0.326 & - & - & - & - & $1.45(1.03-2.05)$ & 0.032 \\
\hline \multicolumn{13}{|c|}{ ADH1B rs1229984 genotype } \\
\hline \multicolumn{13}{|c|}{ Co-dominant model } \\
\hline TT & 204 & 59.1 & 628 & 57.9 & 1 (ref) & & 142 & 55.9 & 408 & 53.7 & 1 (ref) & \\
\hline TC & 123 & 35.7 & 385 & 35.5 & $1.03(0.75-1.41)$ & 0.872 & 100 & 39.4 & 302 & 39.7 & $0.80(0.56-1.15)$ & 0.227 \\
\hline $\mathrm{CC}$ & 18 & 5.2 & 72 & 6.6 & $0.85(0.43-1.62)$ & 0.637 & 12 & 4.7 & 50 & 6.6 & $0.56(0.23-1.27)$ & 0.182 \\
\hline \multicolumn{13}{|l|}{ Dominant model } \\
\hline TT & 204 & 59.1 & 628 & 57.9 & 1 (ref) & & 142 & 55.9 & 408 & 53.7 & 1 (ref) & \\
\hline TC/CC & 141 & 40.9 & 457 & 42.1 & $1.00(0.74-1.35)$ & 0.999 & 112 & 44.1 & 352 & 46.3 & $0.77(0.54-1.09)$ & 0.142 \\
\hline \multicolumn{13}{|l|}{ Additive model } \\
\hline Increment of $\mathrm{C}$ & - & - & - & - & $0.98(0.76-1.25)$ & 0.842 & - & - & - & - & $0.78(0.58-1.04)$ & 0.098 \\
\hline \multicolumn{13}{|c|}{ ALDH2 rs671 and ADH1B rs1229984 genotype } \\
\hline GG and TT & 148 & \begin{tabular}{|l|}
42.9 \\
\end{tabular} & 438 & 40.4 & 1 (ref) & & 98 & 38.6 & 300 & 39.5 & 1 (ref) & \\
\hline GA or TC & 168 & 48.7 & 551 & 50.8 & $1.02(0.74-1.40)$ & 0.915 & 138 & 54.3 & 392 & 51.6 & $1.10(0.77-1.59)$ & 0.607 \\
\hline $\mathrm{AA}$ or $\mathrm{CC}$ & 29 & 8.4 & 96 & 8.8 & $1.09(0.61-1.90)$ & 0.772 & 18 & 7.1 & 68 & 8.9 & $0.68(0.32-1.40)$ & 0.313 \\
\hline
\end{tabular}

Table 4. Association among alcohol consumption, ALDH2 rs671 polymorphism, ADH1B rs1229984

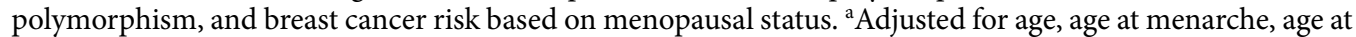
first full term pregnancy, age at menopause, body mass index, smoking status, and alcohol consumption (for the association with ALDH2 or ADH1B) or ALDH2/ADH1B (for the association with alcohol consumption).

It has been reported that both $A D H 1 B$ and $A L D H 2$ present strong association with alcohol dependence. People with the A allele of rs671 display less alcohol dependence, possibly owing to the unpleasant effects of a higher flush response ${ }^{33}$, and those with the rs1229984 His allele also show a decreased risk of alcohol dependence, especially in Asian populations ${ }^{32,34}$. A genome-wide association study for alcohol consumption revealed that the rs671 A allele was associated with decreased prevalence of drinkers and number of drinks, and that the rs1229984 $\mathrm{T}$ allele was associated with fewer drinks but not with drinking status ${ }^{35}$. In this study population, women who carried the GG allele of rs671 consumed alcohol with $>12 \mathrm{~g}$ ethanol/day more often compared to those with the GA/AA genotype $(P$-value $<0.001)$, as in previous studies ${ }^{33,35}$; however, their distribution was similar regardless of rs1229984 genotype. Previous studies included both men and women ${ }^{32,35}$, and sex-differences in terms of alcohol intake pattern ${ }^{35}$ and alcohol metabolism may affect inconsistencies in the results.

Women who carried both the GG and TT genotypes for rs671 and rs1229984, respectively, presented a higher risk of breast cancer when they had ever consumed alcohol or more than $12 \mathrm{~g}$ ethanol per day, suggesting that for those with increased activity of the enzymes involved in alcohol metabolism and detoxification, the effects of alcohol consumption on breast cancer risk are increased. In these populations, alcohol would be eliminated faster than in other populations. Although highly active $A D H 1 B$ and $A L D H 2$ may reduce the effects of alcohol and its toxic metabolites such as acetaldehyde, the effects of alcohol drinking such as intoxication and the recovery period may result in increased alcohol exposure.

Although a study conducted in Korea revealed marginally decreased association between the Lys allele of the $A L D H 2$ gene and breast cancer in postmenopausal women and no association in premenopausal women ${ }^{20}$, our results reveal an increased association between the Lys (A) allele of rs671 and breast cancer in postmenopausal women. The previous study included few premenopausal women, only 226 cases and 209 controls and only 60 cases of postmenopausal women carrying the Lys allele ${ }^{20}$; this may explain the lack of association. Regarding the $A D H 1 B$ gene, other studies have demonstrated no significant association with breast cancer in postmenopausal women ${ }^{36}$ and those aged $50^{27}$, and these observations were consistent with our results. 
This study has certain limitations. First, the existence of selection bias should be considered. To increase comparability, cases and controls were individually matched by age. Although external validity may be limited, the prevalence of variants in $A L D H 2$ and $A D H 1 B$ genes is comparable with that in the general population ${ }^{37}$. Second, recall-bias could affect the results for measurements of alcohol consumption and other covariates. Some patients were recruited while receiving treatment, which may also affect the results. Third, the effects of other genes related to alcohol metabolism, such as Cytochrome P450 2E1, were not considered. Fourth, although this study included a larger sample size compared with previous studies on the association between $A L D H 2, A D H 1 B$, alcohol consumption, and breast cancer, the statistical power may still be limited for elucidating gene-gene and gene-alcohol consumption interactions, and stratified analysis. In addition, some of the non-significant results from our subgroup analysis could be attributed to the low power of this study. Fifth, some variables that may affect both alcohol intake and breast cancer such as diet and exercise, were not considered because of limited available information and may have been incompletely adjusted for.

This study is the first to reveal an independent association between variants of the ALDH2 gene and breast cancer in Asian women with results validated from a large number of cases and controls. Alcohol consumption increased breast cancer risk, but for cases homozygous for the major alleles of $A D H 1 B$ or/and $A L D H 2$ polymorphisms, the increment was more prominent, suggesting that this was a high-risk population for breast cancers associated with alcohol consumption. Further studies with a larger sample size could help confirm the association between alcohol intake and gene interaction and breast cancer risk.

\section{Methods}

Study population. In total, we selected 750 women recently diagnosed with either invasive or in situ breast cancer, as confirmed by histology, at the NCC in Korea between February 2013 and October 2016. Healthy controls were selected from the KoGES, a population-based cohort constructed by the National Research Institute of Health (NIH), and the Centers for Disease Control and Prevention of Korea. Full details of the KoGES are described elsewhere ${ }^{38}$. Female control participants with a history of cancer were excluded, and 3986 women were considered for the study. Among these, 3977 controls provided information on alcohol consumption. All participants were from Korea, and written informed consent was obtained before enrolment. This study was approved by the National Cancer Center Institutional Review Board (IRB No. NCC 2015-0177). All procedures were performed in accordance with the Declaration of Helsinki.

Data collection. All cases and controls were asked to complete a set of interviewer-assisted questionnaires on demographics, medical history, reproductive factors, and lifestyle (including alcohol intake). The subjects were questioned about alcohol consumption, their present drinking status, as well as the total duration of alcohol consumption for both present drinkers and those with a history of alcohol intake. In addition, the type of alcoholic beverage, weekly intake frequency, amount of alcohol consumed on each occasion, and serving sizes were evaluated. The subjects were classified according to drinking status (never and ever). Among ever drinkers, subjects were further classified according to alcohol intake: $\leq 12 \mathrm{~g}$ pure alcohol/day and $>12 \mathrm{~g}$ pure alcohol/day based on the amount of ethanol in a standard drink.

Genotyping and final study population. Genomic DNA was extracted from peripheral blood leukocytes and genotyped using the Korea Biobank Array with 833,000 SNPs. The Korea Biobank Array is a chip optimized for genetic studies in the Korean population. Full details on Korea Biobank Array are described elsewhere ${ }^{39,40}$. Of the 750 breast cancer cases and 3977 controls, 5 cases were excluded owing to a low call rate of $<97 \%(n=1)$ and family relationships $(n=4)$; after quality control, 745 cases and 3977 controls were evaluated. SNPs were excluded for low quality based on SNPolisher analysis $(n=36,816)$, low call rate $<95 \%$ in either the cases or controls $(n=371)$, deviation from Hardy-Weinberg equilibrium $\left(p\right.$-value $\left.<1 \times 10^{-6}\right)$ in the controls $(n=713)$, and monomorphic characteristics in our population $(n=107,204)$. In total, 688,196 markers were evaluated for quality control.

The SNPs rs671 and rs1229984, in the $A L D H 2$ and $A D H 1 B$ genes, respectively, were analyzed. The cases and controls were individually matched by age at a 1:3 ratio, and ultimately 623 breast cancer cases and 1845 controls aged 40 or above were included in the final analysis. Discrepancies between the evaluated cases and controls were $0 \%$ and $0 \%$ for rs 671 and $0 \%$ and $0.6 \%$ for rs 1229984 , with a $P$-value of 0.922 . These SNPs had minor allelic frequencies of $15.5 \%$ and $25.2 \%$ and met the Hardy-Weinberg equilibrium in the control samples.

Validation of the association between ALDH2 polymorphism and breast cancer. Data from 2143 breast cancer patients who were recruited as part of the KoGES were evaluated according to their sex, age, and genotype to validate the association between $A L D H 2$ polymorphism and breast cancer. Demographic and lifestyle information, including on alcohol intake, was unavailable for these patients. Peripheral blood DNA was genotyped using an Affymetrix Genome-wide Human SNP Array 6.0 (Affymetrix Inc., Santa Clara, CA, USA). As ALDH2 (rs671) was not included in the array, genotype imputation for rs671 was performed. The SHAPEIT (v2.r837) was used for prephasing, and imputation was performed using IMPUTE2 (2.3.2). Data from the 1000 Genome Project phase 3 East-Asian Ancestry sample $(n=504)$ were applied as a reference panel. The quality control process and imputation was conducted as follows: among all subjects, those with a sex mismatch $(n=3)$ were excluded. No subjects showed a low call rate or family relationships. SNPs were excluded in cases of low call rate $<95 \%(n=151,323)$, deviation from Hardy-Weinberg equilibrium $\left(p\right.$-value $\left.<1 \times 10^{-6}\right)$ in the controls $(n=897)$, or monomorphic traits in the population $(n=1710)$. In total, 513,738 markers were subjected to quality control. After imputation, the quality score was $\mathrm{R}^{2}=0.57$. The age distribution of the 2143 breast cancer patients and 3977 controls is presented in Appendix Table 1. 
Statistical analysis. The relationship between alcohol consumption and breast cancer risk was assessed with a simple logistic regression and a multiple logistic regression adjusted for age at menarche, age at first full term pregnancy, age at menopause, body mass index, smoking status, and rs671/rs1229984 genotype. The relationship between rs671 genotype, rs1229984 genotype, and breast cancer risk was additionally assessed with a simple and a multiple logistic regression adjusted for age at menarche, age at first full term pregnancy, age at menopause, body mass index, smoking status, and alcohol consumption. To assess the association between each SNP and breast cancer, the codominant, dominant, and additive models were considered. In addition, the combined effects of rs671 and rs1229984 genotype on breast cancer were assessed.

The $A L D H 2$ and $A D H 1 B$ genotypes and alcohol intake status were collectively studied to evaluate their combined effect on breast cancer risk. Stratified by $A L D H 2, A D H 1 B$, and a combination of $A L D H 2 / A D H 1 B$ genotypes, the association among alcohol consumption itself, daily alcohol intake, and breast cancer was evaluated with odds ratio (OR) and $P$-value. In addition, after stratification by menopausal status, the relationship among alcohol consumption, rs671, and/or rs 1229984 genotypes and breast cancer risk was assessed.

To validate the association between $A L D H 2$ polymorphism and breast cancer risk, the OR and $P$-values were presented, and adjusted for age between 2143 breast cancer cases and 3977 controls (all of the controls considered for the study) from KoGES. These analyses were performed with PLINK v.1.07 ${ }^{41}$ and R statistical software version 3.2.2 (R Foundation, Vienna, Austria).

Ethical approval and informed consent. Informed consent was collected for all cases and controls. This study was approved by the National Cancer Center Institutional Review Board (IRB No. NCC 2015-0177).

\section{Data availability}

Data is available from the authors by request.

Received: 14 February 2019; Accepted: 12 February 2020;

Published online: 16 April 2020

\section{References}

1. Peacock, A. et al. Global statistics on alcohol, tobacco and illicit drug use: 2017 status report. Addiction 10, 14234 (2018).

2. Baan, R. et al. Carcinogenicity of alcoholic beverages. Lancet Oncol. 8, 292-293 (2007).

3. Lindahl, R. Aldehyde dehydrogenases and their role in carcinogenesis. Crit. Rev. Biochem. Mol. Biol. 27, 283-335, https://doi. org $/ 10.3109 / 10409239209082565$ (1992).

4. Druesne-Pecollo, N. et al. Alcohol and genetic polymorphisms: effect on risk of alcohol-related cancer. Lancet Oncol. 10, 173-180, https://doi.org/10.1016/S1470-2045(1009)70019-70011 (2009).

5. Bosron, W. F. \& Li, T. K. Genetic polymorphism of human liver alcohol and aldehyde dehydrogenases, and their relationship to alcohol metabolism and alcoholism. Hepatology. 6, 502-510 (1986).

6. Jelski, W. \& Szmitkowski, M. Alcohol dehydrogenase (ADH) and aldehyde dehydrogenase (ALDH) in the cancer diseases. Clin. Chim. Acta. 395, 1-5, https://doi.org/10.1016/j.cca.2008.1005.1001 Epub 2008 May 1018 (2008).

7. Couzigou, P., Coutelle, C., Fleury, B. \& Iron, A. Alcohol and aldehyde dehydrogenase genotypes, alcoholism and alcohol related disease. Alcohol. Alcohol Suppl. 2, 21-27 (1994).

8. Scoccianti, C., Lauby-Secretan, B., Bello, P. Y., Chajes, V. \& Romieu, I. Female breast cancer and alcohol consumption: a review of the literature. Am. J. Prev. Med. 46, S16-25, https://doi.org/10.1016/j.amepre.2013.1010.1031 (2014).

9. Chang, J. S., Hsiao, J. R. \& Chen, C. H. ALDH2 polymorphism and alcohol-related cancers in Asians: a public health perspective. J. Biomed. Sci. 24, 19, https://doi.org/10.1186/s12929-12017-10327-y (2017).

10. Slade, T. et al. Birth cohort trends in the global epidemiology of alcohol use and alcohol-related harms in men and women: systematic review and metaregression. BMJ Open. 6, e011827. 10.011136/bmjopen-012016-011827 (2016).

11. Youlden, D. R., Cramb, S. M., Yip, C. H. \& Baade, P. D. Incidence and mortality of female breast cancer in the Asia-Pacific region. Cancer Biol. Med. 11, 101-115, https://doi.org/10.7497/j.issn.2095-3941.2014.7402.7005 (2014).

12. Brennan, P. et al. Pooled analysis of alcohol dehydrogenase genotypes and head and neck cancer: a HuGE review. Am. J. Epidemiol. 159, 1-16 (2004).

13. Cao, Y., Willett, W. C., Rimm, E. B., Stampfer, M. J. \& Giovannucci, E. L. Light to moderate intake of alcohol, drinking patterns, and risk of cancer: results from two prospective US cohort studies. BMJ. 351, h4238 (2015).

14. Trentham-Dietz, A. et al. Modification of breast cancer risk according to age and menopausal status: a combined analysis of five population-based case-control studies. Breast Cancer Res. Treat. 145, 165-175, https://doi.org/10.1007/s10549-014-2905-y (2014).

15. Pabalan, N., Jarjanazi, H., Sung, L., Li, H. \& Ozcelik, H. Menopausal status modifies breast cancer risk associated with the myeloperoxidase (MPO) G463A polymorphism in Caucasian women: a meta-analysis. PLoS One 7, e32389, https://doi.org/10.1371/ journal.pone.0032389 (2012).

16. Cai, Q., Wu, J., Cai, Q., Chen, E. Z. \& Jiang, Z. Y. Association between Glu504Lys polymorphism of ALDH2 gene and cancer risk: a meta-analysis. PLoS One. 10, e0117173, 10.0111371/journal.pone.0117173. eCollection 0112015 (2015).

17. Oze, I. et al. Alcohol drinking and esophageal cancer risk: an evaluation based on a systematic review of epidemiologic evidence among the Japanese population. Jpn J Clin Oncol. 41, 677-692, https://doi.org/10.1093/jjco/hyr1026. Epub 2011 Mar 1023. (2011).

18. Zhao, S., Du, X. M., Ma, S. S. \& Wang, L. M. Association between aldehyde dehydrogenase 2 (ALDH2) Glu504Lys polymorphism and susceptibility to colorectal cancer: a meta-analysis. Genet. Mol. Res. 15(3), gmr7872, https://doi.org/10.4238/gmr.15037872 (2016).

19. Kawase, T. et al. Interaction of the effects of alcohol drinking and polymorphisms in alcohol-metabolizing enzymes on the risk of female breast cancer in Japan. J Epidemiol 19, 244-250. Epub 2009 Aug 2008 (2009).

20. Choi, J. Y. et al. Role of alcohol and genetic polymorphisms of CYP2E1 and ALDH2 in breast cancer development. Pharmacogenetics. 13, 67-72, https://doi.org/10.1097/1001.fpc.0000054060.0000098065.fc (2003).

21. Sangrajrang, S. et al. Genetic polymorphisms in folate and alcohol metabolism and breast cancer risk: a case-control study in Thai women. Breast Cancer Res Treat. 123, 885-893, https://doi.org/10.1007/s10549-10010-10804-10544. Epub 12010 Feb 10524 (2010).

22. Sadetzki, S., Bensal, D., Novikov, I. \& Modan, B. The limitations of using hospital controls in cancer etiology - one more example for Berkson’s bias. Eur. J. Epidemiol. 18, 1127-1131, https://doi.org/10.1023/B:EJEP.0000006634.49205.c5 (2003).

23. Yagi, T. et al. Aldehyde dehydrogenase 2 genotype in tolerability of alcohol contained in paclitaxel in Japanese breast cancer patients. Breast Cancer 26, 229-234, https://doi.org/10.1007/s12282-018-0918-9 (2019).

24. Singh, N. P. \& Khan, A. Acetaldehyde: genotoxicity and cytotoxicity in human lymphocytes. Mutat. Res. 337, 9-17 (1995). 
25. Lee, S. L., Hoog, J. O. \& Yin, S. J. Functionality of allelic variations in human alcohol dehydrogenase gene family: assessment of a functional window for protection against alcoholism. Pharmacogenetics. 14, 725-732 (2004).

26. Mao, N. et al. Association between alcohol dehydrogenase-2 gene polymorphism and esophageal cancer risk: a meta-analysis. World J. Surg. Oncol. 14, 191, https://doi.org/10.1186/s12957-12016-10937-y (2016).

27. Lilla, C., Koehler, T., Kropp, S., Wang-Gohrke, S. \& Chang-Claude, J. Alcohol dehydrogenase 1B (ADH1B) genotype, alcohol consumption and breast cancer risk by age 50 years in a German case-control study. Br. J. Cancer. 92, 2039-2041, https://doi. org/10.1038/sj.bjc.6602608 (2005).

28. Terry, M. B. et al. Alcohol metabolism, alcohol intake, and breast cancer risk: a sister-set analysis using the Breast Cancer Family Registry. Breast Cancer Res Treat. 106, 281-288, https://doi.org/10.1007/s10549-10007-19498-10547 Epub 12007 Feb 10541 (2007).

29. Visvanathan, K. et al. Alcohol dehydrogenase genetic polymorphisms, low-to-moderate alcohol consumption, and risk of breast cancer. Alcohol. Clin. Exp. Res. 31, 467-476, https://doi.org/10.1111/j.1530-0277.2006.00334.x (2007).

30. Liu, J. et al. Alcohol Drinking Mediates the Association between Polymorphisms of ADH1B and ALDH2 and Hepatitis B-Related Hepatocellular Carcinoma. Cancer Epidemiol. Biomarkers amp; Prev. 25, 693-699, https://doi.org/10.1158/1055-9965.Epi-15-0961 (2016).

31. Park, S. et al. Attributable fraction of alcohol consumption on cancer using population-based nationwide cancer incidence and mortality data in the Republic of Korea. BMC Cancer 14, 420, https://doi.org/10.1186/1471-2407-14-420 (2014).

32. Bierut, L. J. et al. ADH1B is associated with alcohol dependence and alcohol consumption in populations of European and African ancestry. Mol. psychiatry 17, 445 (2012).

33. Quillen, E. E. et al. ALDH2 is associated to alcohol dependence and is the major genetic determinant of "daily maximum drinks" in a GWAS study of an isolated rural Chinese sample. Am. J. Med. Genet. Part. B: Neuropsychiatric Genet. 165, 103-110 (2014).

34. Edenberg, H. J. The genetics of alcohol metabolism: role of alcohol dehydrogenase and aldehyde dehydrogenase variants. Alcohol. Res. Health 30, 5 (2007).

35. Jorgenson, E. et al. Genetic contributors to variation in alcohol consumption vary by race/ethnicity in a large multi-ethnic genomewide association study. Mol. Psychiatry 22, 1359-1367, https://doi.org/10.1038/mp.2017.101 (2017).

36. Hahn, M., Simons, C. C., Weijenberg, M. P. \& van den Brandt, P. A. Alcohol drinking, ADH1B and ADH1C genotypes, and the risk of postmenopausal breast cancer by hormone receptor status: The Netherlands Cohort Study on Diet and Cancer. Carcinogenesis (2018).

37. Eng, M. Y., Luczak, S. E. \& Wall, T. L. ALDH2, ADH1B, and ADH1C genotypes in Asians: a literature review. Alcohol. Res. Health 30, 22 (2007).

38. Kim, Y. \& Han, B. G. Cohort Profile: The Korean Genome and Epidemiology Study (KoGES) Consortium. Int. J. Epidemiol. 46, 1350, https://doi.org/10.1093/ije/dyx1105 (2017).

39. Kim, Y. J., Moon, S. H. \& Kim, B. J. The Korea Biobank Array Project. Public Health Weekly Report, KCDC 8, 670-674.

40. Moon, S. et al. The Korea Biobank Array: Design and Identification of Coding Variants Associated with Blood Biochemical Traits. Sci. Rep. 9, 1382, https://doi.org/10.1038/s41598-018-37832-9 (2019).

41. Purcell, S. et al. PLINK: a tool set for whole-genome association and population-based linkage analyses. Am. J. Hum. Genet. 81, 559-575 (2007)

\section{Acknowledgements}

This work was supported by the National Cancer Center Grant (NCC-1810101). This study used data from the Korean Genome Analysis Project (4845-301), the Korean Genome and Epidemiology Study (4851-302), and the Korea Biobank Project (4851-307, KBP-2014-041), which were supported by the Korea Centers for Disease Control and Prevention, Republic of Korea.

\section{Author contributions}

Concept and design: Boyoung Park, Eun-Sook Lee, So-Youn Jun. Acquisition of data: Eun-Sook Lee, So-Youn Jung, See youn Lee, Han-Sung Kang, Eun-Gyeong Lee, Jai Hong Han. Analysis and interpretation of data: Boyoung Park, Ji-Hyun Kim, Eun-Gyeong Lee, Jai Hong Han. Drafting of the article: Boyoung Park, See youn Lee, Han-Sung Kang. Final approval: All authors.

\section{Competing interests}

The authors declare no competing interests.

\section{Additional information}

Supplementary information is available for this paper at https://doi.org/10.1038/s41598-020-62361-9.

Correspondence and requests for materials should be addressed to B.P.

Reprints and permissions information is available at www.nature.com/reprints.

Publisher's note Springer Nature remains neutral with regard to jurisdictional claims in published maps and institutional affiliations.

Open Access This article is licensed under a Creative Commons Attribution 4.0 International License, which permits use, sharing, adaptation, distribution and reproduction in any medium or format, as long as you give appropriate credit to the original author(s) and the source, provide a link to the Creative Commons license, and indicate if changes were made. The images or other third party material in this article are included in the article's Creative Commons license, unless indicated otherwise in a credit line to the material. If material is not included in the article's Creative Commons license and your intended use is not permitted by statutory regulation or exceeds the permitted use, you will need to obtain permission directly from the copyright holder. To view a copy of this license, visit http://creativecommons.org/licenses/by/4.0/.

(c) The Author(s) 2020 